\title{
Médicos, especialistas, políticos y funcionarios en la organización centralizada de la profilaxis de las enfermedades venéreas en la Argentina (1930-1954)
}

\author{
Carolina Biernat
}

Universidad Nacional de Quilmes

El trabajo analiza la creación en la Argentina, entre los años 1930 y 1954, de una estructura administrativa nacional, orientada a la prevención y el tratamiento de las enfermedades venéreas. Dicho esfuerzo responde a un proyecto político de un grupo de médicos, quienes intentaron dar respuesta a los problemas sociales desde el ámbito de la higiene y colonizar la estructura burocrática del Estado en su calidad de expertos. Por otro lado, indaga acerca del proceso de especialización de las disciplinas encargadas de estas enfermedades y su reconocimiento oficial como especialidades médicas.

PALABRAS CLAVE: Enfermedades venéreas, profilaxis, legislación, burocracia, especialidades médicas.

This work analyzes the creation in Argentina, between 1930 and 1954, of a national administrative structure, oriented to the prevention and treatment of venereal diseases. Such an effort respond to the political project of a group of physicians, who tried to give an answer to the social problems from the hygiene field and seize the bureaucratic structure of the state in their role of experts. Additionally, it inquires into the specialization process of the disciplines responsible for the treatment of the venereal diseases and their consequent recognition as medical specialties.

KEYWORDS: Venereal diseases, prophylaxis, legislation, bureaucracy, medical specialties.

La preocupación por las enfermedades de transmisión sexual en la Argentina, en consonancia con la de la mayor parte de los países occidentales, se extendió en las últimas décadas del siglo XIX. Junto con el alcoholismo y la tuberculosis, formaron parte de un núcleo patológico cuyas causas y posibles soluciones se explicaron en el marco de problemas sociales más generales. En virtud de ello, estas enfermedades fueron incorporadas a la agenda política reformista, que incluía a liberales, conservadores, católicos, radicales, socialistas y anarquistas, y que bregaba por la 
necesidad de un reordenamiento social, de la mejora de las condiciones de vida de los sectores populares y de la vigilancia y moralización de la población. ${ }^{1}$

Durante el último cuarto del siglo XIX, el control de la propagación de los males venéreos se concentró en los esfuerzos por reglamentar el ejercicio de la prostitución. Médicos, legisladores, administradores y representantes de diferentes grupos de interés y opinión encontraron consenso en sucesivas leyes municipales que legalizaron la prostitución, siempre que los establecimientos donde se desempeñara contaran con la debida autorización de los gobiernos locales y las mujeres que la practicaran fueran sometidas a regulares inspecciones sanitarias. ${ }^{2}$

De todos modos, esta tranquilidad respecto a la amenaza de las enfermedades "secretas" sobre el conjunto de la población comenzó a ser puesta en cuestión en las primeras décadas del siglo siguiente. La renovada preocupación por la morbilidad venérea estuvo asociada a un conjunto de discusiones más generales, donde nuevos y viejos problemas se combinaron, dando lugar a su reaparición en la agenda política.

En primer lugar, la sospecha acerca del incremento en los índices de padecimiento de enfermedades venéreas - de difícil comprobación, puesto que la asistencia pública contaba solamente con registros estadísticos de las mujeres que comerciaban con su cuerpo o de los pocos varones que se acercaban a las instituciones sanitarias oficiales para tratarse- se ligó al debate acerca de los límites que el sistema "reglamentarista" de la prostitución presentaba. Al poco tiempo de ser puesta en práctica, la norma fue cuestionada por médicos, políticos, legisladores y amplios sectores de la opinión pública, por su supuesta ineficacia. Por un lado, se criticó el carácter unilateral del control sanitario basado en el argumento de considerar a las prostitutas como las exclusivas propiciadoras del contagio. Por otro, se denunció la facilidad demostrada por muchas mujeres a la hora de evitar revisiones o resultados positivos, y hasta la complicidad de funcionarios políticos y policiales con los encargados de los burdeles, para evitar las dis-

1 Sobre la relación entre "enfermedades sociales" y "cuestión social" en la Argentina véase Armus, Diego: "Consenso, conflicto y liderazgo en la lucha contra la tuberculosis. Buenos Aires 18701950” en Suriano, Juan (comp.): La cuestión social en Argentina, 1870-1943, La Colmena, Buenos Aires, agosto de 2004 (segunda edición), págs. 191-216.

2 Acerca del proceso de reglamentación de la prostitución en Buenos Aires y en Rosario véase Guy, Donna: El sexo peligroso. La prostitución legal en Buenos Aires (1875-1975), Sudamericana, Buenos Aires, 1994, y Múgica, María Luisa: Sexo bajo control. La prostitución reglamentada. Rosario entre 1900 y 1912, Universidad Nacional de Rosario, 2001. 
posiciones oficiales respecto a las inspecciones médicas periódicas de las prostitutas. Por último, se puso en evidencia el creciente número de mujeres de "mala vida" sin patente, que ejercían su trabajo fuera de toda posibilidad de ser controladas por las autoridades sanitarias. De este modo, comenzó a insistirse en la necesidad de abolir el sistema "reglamentarista" de la prostitución, como requisito para detener el incremento de las dolencias venéreas. ${ }^{3}$

Un segundo nivel de discusiones estuvo asociado al impacto que los cambios sociales produjeron en el universo de certezas morales imperante en la época. Desde el punto de vista de un doble patrón de moralidad sexual, la existencia de prostíbulos reglamentados permitía cumplir con la "exigencia" social de experiencia carnal para los solteros que pretendían formar una familia y, a los varones casados, "descargar" los impulsos sexuales que no podían ser satisfechos dentro de un matrimonio orientado a la reproducción pero vacío de placer. Ahora bien, la creciente incorporación de las mujeres al mercado de trabajo, sobre todo de aquellas que pertenecían a los sectores populares, fue interpretada por muchos de sus contemporáneos como una traición a sus "deberes maternales" y como un riesgo para su "virtud". Muchas de ellas fueron consideradas como instigadoras de los varones a la mala conducta y responsables del contagio de las patologías "secretas".

Un tercer aspecto ligado a la renovada preocupación acerca de los males venéreos se vincula con el fortalecimiento del discurso eugenésico en los ámbitos académicos, políticos e institucionales. Para esta corriente de pensamiento que, partiendo de la premisa de que todos los caracteres de los seres humanos son hereditarios, tanto las capacidades y talentos como la propensión a la enfermedad, se proponía mejorar la "raza" blanca a través de la reproducción de determinados individuos o grupos humanos calificados como "mejores", inhibiendo la multiplicación de otros grupos o individuos considerados "inferiores" o "indeseables"; las enfermedades sexuales eran consideradas como una amenaza para la salud de la población y para su acervo hereditario. De ahí que sus seguidores, de las más variadas extracciones ideológicas y formación profesional, hayan insistido

3 Un análisis de las críticas al sistema "reglamentarista" puede verse en Gramático, Karin: "Obreras, prostitutas y mal venéreo. Un Estado en busca de la profilaxis" en Gil Lozano, Fernanda; Pita, Valeria, e Ini, María Gabriela: Historia de las mujeres en la Argentina, Taurus, Buenos Aires, 2000, vol. II, págs. 117-119.

4 Ibídem, págs. 119 y 125-127. 
en una legislación que asegurase la educación sexual de los futuros progenitores, formando su conciencia de reproductores "responsables"; la instrucción profiláctica de aquellos que, cediendo a sus impulsos más viscerales, se pusieran en contacto con posibles focos de infección; y la obligatoriedad del certificado prenupcial, a fin de identificar los casos de enfermos venéreos y evitar las funestas consecuencias de su apareamiento para el "porvenir de la raza".

Un cuarto nivel de discusión se centró en la necesidad de establecer, a nivel nacional, un sistema sanitario encargado de la prevención y el tratamiento de las enfermedades venéreas. Como en tantas otras áreas de la atención sanitaria, los distintos niveles de gobierno y las esferas pública y privada se superponían en la asistencia de estas dolencias, combinando diferentes grados de autonomía y dando como resultado un servicio ineficiente. El Departamento Nacional de Higiene fue visualizado como escenario privilegiado para la organización de una estructura administrativa que asegurara la centralización de la asistencia de las afecciones venéreas. De todos modos, resultaba indispensable un ordenamiento legal que lo dotara de capacidades institucionales y recursos materiales. Para ello fue necesario apelar a la acción parlamentaria, espacio en el que se hizo evidente la rivalidad de intereses y proyectos en torno a la organización de un sistema nacional de profilaxis venérea, que involucraba a funcionarios, especialistas, políticos y numerosos grupos de la sociedad civil.

Un último aspecto considerado en los debates fue el del reclamo de reconocimiento oficial de los médicos especialistas en patologías venéreas. Tradicionalmente atendidas por dermatólogos o urólogos, estas enfermedades comenzaron a ser objeto de investigación y tratamiento de venerólogos y dermosifilógrafos. Estos nuevos expertos bregaron, desde la segunda mitad de la década de los veinte, por un espacio en el campo académico, en el profesional y en el sistema sanitario, a través de la creación de cátedras en las universidades nacionales, de publicaciones específicas, de su incorporación en la asistencia de la salud de los distintos niveles de gobierno y en las nacientes reparticiones encargadas de la gestión de la profilaxis y tra-

5 Acerca del surgimiento y consolidación de las ideas eugenésicas en Latinoamérica: Stepan, Nancy Leys: The Hour of Eugenics. Race, Gender and Nation in Latin America, Cornell University Press, Ithaca and London, 1991. Sobre la eugenesia en la Argentina véase Palma, Héctor: Gobernar es seleccionar. Apuntes sobre la Eugenesia, Jorge Baudino Ediciones, Buenos Aires, 2002 y Miranda, Marisa y Vallejo, Gustavo (comps.): Darwinismo social y eugenesia en el mundo latino, Siglo XXI de Argentina Editores, Buenos Aires, 2005. 
tamiento de las enfermedades venéreas. Paralelamente reclamaron el reconocimiento oficial de la venerología y de la dermatosifilografía, como especialidades de la medicina, y el acceso a los cargos públicos a través de concursos probatorios de idoneidad y de experiencia previa del candidato en la materia.

El conjunto de estos planteamientos, defendidos desde posiciones muy diversas, confluyeron en la discusión y la sanción de la ley de Profilaxis de Enfermedades Venéreas promulgada en diciembre de 1936. Dicha normativa dispuso la creación de una repartición, en el seno del Departamento Nacional de Higiene, encargada de la organización y centralización de la prevención y tratamiento de los males venéreos en todo el país; la incorporación en los planes de estudio de la educación formal de la instrucción sexual; la instauración de campañas populares de profilaxis individual; el certificado prenupcial gratuito y obligatorio para los varones y la prohibición del establecimiento de casas o locales donde se ejerciera la prostitución o se incitara a ella.

El presente trabajo se centra en el análisis de los dos últimos aspectos enunciados: la creación de una estructura administrativa nacional, capaz de dar respuesta a la prevención y al tratamiento de las enfermedades venéreas, y el proceso de especialización de los médicos encargados de llevar a cabo esta tarea en las instituciones sanitarias públicas y privadas. El primero de ellos parece responder a un proyecto político mucho más ambicioso de un grupo de profesionales médicos quienes, teniendo como epicentro al Departamento Nacional de Higiene, intentaron dar respuesta a los problemas sociales desde el ámbito de la higiene y colonizar la estructura burocrática del Estado en su calidad de expertos.

Si bien este proceso de consolidación de la presencia de los galenos en el aparato estatal se había iniciado en las últimas décadas del siglo XIX, en los años treinta de la siguiente centuria se acentuó en términos cuantitativos y cualitativos. Por un lado, la creciente intervención estatal en la regulación de la vida económica y social expandió su burocracia y las posibilidades de acceder a ella. Por otro lado, la demanda oficial de profesionales médicos ya no estaba vinculada solamente a los esporádicos brotes epidémicos, tal y como sucedía en el período anterior, sino que se asoció a la mejora de la salud física y moral de la población presente y futura. En este sentido, la profilaxis de las enfermedades venéreas compartió la agenda de preocupaciones oficiales con otros temas como el tratamiento de la tuberculosis o la reducción de los índices de mortalidad 
infantil y el estímulo de la natalidad a través de la protección de la madre y el niño. ${ }^{6}$

Por último, el trabajo se propone indagar acerca del proceso de especialización de las disciplinas encargadas del tratamiento de las enfermedades venéreas y su consecuente reconocimiento oficial como especialidades médicas. En este recorrido se aspira a relacionar el surgimiento de estas disciplinas como espacios de formación y consolidación de los cuadros burocráticos intermedios, que tuvieron la responsabilidad de organizar las nuevas agencias estatales dentro del Departamento Nacional de Higiene e implementar las medidas oficiales de profilaxis venérea.

\section{Prevención y tratamiento de las enfermedades venéreas: problema de todos o de los especialistas}

La prevención y el tratamiento de las patologías venéreas, durante las primeras décadas del siglo $\mathrm{XX}$, estuvieron a cargo de un conjunto de organizaciones, públicas y privadas, de jurisdicción nacional o local, que respondían a diversos objetivos e intereses.

En el ámbito de la sociedad civil, una de las instituciones de mayor prestigio que asumió el compromiso de prevenir el contagio de las enfermedades sexuales fue la Liga Argentina de Profilaxis Social. Fundada por el médico Alfredo Fernández Verano en el año 1921, encontró legitimidad en los principios eugenistas, de creciente ascendiente en los más variados círculos de intelectuales, profesionales y políticos de la entreguerra, según los cuales estas patologías constituían una de las causas de la debilidad constitucional congénita que impedían la reproducción saludable de la población. Además, contó con el patrocinio del Círculo Médico Argentino y del Centro de Estudiantes de Medicina, y su junta consultiva estuvo integrada por personalidades de peso en el mundo sanitario y político.

La Liga tenía como objetivo evitar y combatir la propagación de las patologías venéreas que "por su extremada difusión, siempre 'in crescendo' y, sobre todo, por sus consecuencias hereditarias" fueron consideradas,

6 Sobre el período inicial del proceso de colonización del aparato estatal por parte de los médicos véase González Leandri, Ricardo: "Madurez y poder. Médicos e instituciones sanitarias en la Argentina a fines del siglo XIX”, Entrepasados, n. ${ }^{2}$ 27, Buenos Aires, 2005, págs. 133-150. Ejemplos de este proceso en otras disciplinas: Neiburg, Federico, y Plotkin, Mariano (compiladores): Intelectuales y expertos. La constitución del conocimiento social en la Argentina, Paidós, Buenos Aires, 2004. 
por ella, como "las que más serios peligros representan para el individuo, la sociedad y el porvenir de la raza". Para lograrlo se propuso obtener de los poderes públicos la legislación pertinente; instalar dispensarios antivenéreos gratuitos o de tarifa reducida; difundir, por todos los medios posibles, los conocimientos necesarios para crear la conciencia sanitaria popular sobre enfermedades venéreas; estimular la profilaxis personal, abaratando y divulgando el uso de medios profilácticos; combatir la pornografía y el curanderismo; propiciar y estimular entre los profesionales las investigaciones referentes a estos puntos e instituir el seguro popular contra las enfermedades venéreas. ${ }^{7}$

Para lograr este propósito la Liga Argentina de Profilaxis Social aglutinó, además del esfuerzo de un conjunto importante de médicos, el apoyo de amplios sectores de la sociedad y una relativa atención de los poderes públicos a sus demandas. Su boletín, de 2000 ejemplares mensuales, se distribuyó entre las organizaciones médicas, de estudios sociales y de beneficencia, más representativas del país. Casas comerciales como farmacias, droguerías, tabacaleras, cervecerías, o distribuidoras de alimentos editaron desinteresadamente carteles y folletos de propaganda de la Liga.

Pese a lo ambicioso de sus objetivos y de la legitimidad social de la institución, la Liga centró su actividad en aspectos fundamentalmente preventivos de las enfermedades venéreas. En primer lugar, el reclamo a los poderes públicos, de orden nacional y municipal, para que reglamentaran la prostitución, establecieran dispensarios para el tratamiento de las afecciones venéreas, instauraran la obligatoriedad del certificado prenupcial, e impartieran educación sexual en las escuelas. En segundo lugar, el dictado de conferencias en profesorados y magisterios de la Capital Federal y ciudades del interior del país, patrocinadas por el Consejo Nacional de Educación, y la organización de campañas profilácticas que incluían la distribución de folletos, charlas informativas y proyección de películas. Por último, a partir del año 1931, la instalación de consultorios prenupciales de concurrencia voluntaria en los locales de la Liga que en sus primeros tres años de existencia recibieron cerca de 2.000 consultas. ${ }^{8}$

7 Boletín de la Liga Argentina de Profilaxis Social, Año I, n. ${ }^{\circ}$, Buenos Aires, 30 de septiembre de 1921, págs. 1-3.

8 Ibídem, págs. 4-7 y n. ${ }^{\circ}$ 7, y marzo-junio de 1922, pág. 184 y Fernández Verano, Alfredo; Ascheri, Armando, y Fairstein, David: "Liga Argentina de Profilaxis Social. Consultorio pre-nupcial. Resultados obtenidos en los tres primeros años de funcionamiento", La Semana Médica, Buenos Aires, 6 de diciembre de 1934, págs. 1791-1794. 
Las actividades de la institución presidida por Verano corrieron en paralelo con los esfuerzos de los higienistas socialistas. Desde una posición que no descartaba los postulados de la eugenesia acerca de los efectos nocivos de las enfermedades venéreas sobre el futuro de la población, pero que reconocía la capacidad de la sociedad, y en especial de los sectores populares, de transformar la determinación de la herencia a través de la incorporación de principios y hábitos relacionados con su función reproductiva, se concentraron en un programa que, además de incluir las directivas higiénicas para eliminar las dolencias venéreas, llamaba hacia una reflexión más amplia sobre la sexualidad, capaz de construir una nueva fisonomía moral en el medio obrero.

Este programa reformista de los socialistas se plasmó, por un lado, en una intensa labor parlamentaria para obtener una legislación que protegiera a la sociedad de la amenaza de las enfermedades venéreas y, por otro, en el trabajo de sus asociaciones para informar a los sectores populares acerca de los conocimientos médicos y profilácticos de estas dolencias, formarlos en una nueva ética de relaciones entre los sexos y construir una opinión pública capaz de torcer el rumbo de las decisiones políticas referidas a la profilaxis de los "males secretos". Ejemplo de estas asociaciones fueron la Sociedad Luz, que a través de la organización de conferencias, la distribución de cartillas y la publicación de una colección de escritos bajo el nombre "El problema sexual" intentó construir una nueva configuración moral y sanitaria entre los trabajadores; o el Comité Argentino Uruguayo de la Federación Internacional de Abolicionistas, que defendía, desde uno y otro lado del Río de la Plata, la abolición de la prostitución legalizada, la constitución de un sistema de tratamiento médico gratuito para todos los pacientes con enfermedades venéreas, el divorcio, la reforma de las leyes sobre paternidad, la mejora de las condiciones de trabajo para mujeres y niños, la educación sexual en las escuelas primarias y secundarias y el cierre de los "negocios de entretenimientos obscenos".

Si la tarea preventiva del contagio de enfermedades venéreas estuvo organizada por instituciones de la sociedad civil, el panorama de la atención de estas dolencias involucró a las esferas pública y privada, y a los distintos

9 Sobre la labor de profilaxis social de la Sociedad Luz, se puede consultar Barrancos, Dora: "Socialismo, higiene y profilaxis social, 1900-1930", en Lobato, Mirta (comp.): Política, médicos y enfermedades, Lecturas de historia de la salud en la Argentina, Universidad de Mar del Plata-Biblos, Mar del Plata, 1996, págs. 117-149. Acerca del Comité Argentino Uruguayo de la Federación Internacional de Abolicionistas: Guy, Donna: El sexo peligroso..., págs. 124-125. 
niveles del gobierno federal. Si bien a partir del año 1927 el Departamento Nacional de Higiene contó con una Sección de Profilaxis de la Lepra, Sífilis y Enfermedades Venéreas, que se encargó de organizar dispensarios antivenéreos en zonas portuarias y en el interior del país, esta repartición no estaba dotada de la facultad de ejercer la superintendencia sobre los centros de atención de carácter provincial, municipal o particular. La imposibilidad de este organismo de centralizar la profilaxis de las enfermedades venéreas dio como resultado el fortalecimiento de una estructura de atención caracterizada por la existencia de una multiplicidad de instituciones con distintos niveles de autonomía jurisdiccional, cuyas funciones tendían a superponerse. Ejemplo de ello es la ciudad de Buenos Aires donde los dispensarios venerológicos, creados en 1919 bajo la órbita de la Asistencia Pública de la municipalidad, convivían con los puestos de control sanitario instalados en el puerto, dependientes del Departamento Nacional de Higiene; con los servicios externos de determinados hospitales, como el del Ramos Mejía donde funcionaba la Cátedra de Clínica Dermatosifilográfica, dependiente de la Facultad de Ciencias Médicas de la Universidad de Buenos Aires; con servicios sociales de distintas sociedades mutuales, como la Asociación Española de Socorros Mutuos, y con clínicas privadas. Mientras que las primeras instituciones encontraban la mayor parte de su público en los sectores populares — quienes recurrían a ellas en virtud de su gratuidad-, las dos últimas estaban orientadas hacia la clientela proveniente de grupos sociales con mayores recursos económicos y más sensibles a la penalización moral de padecer una enfermedad "secreta". ${ }^{10}$

Tampoco existía un tratamiento único en todo el país para combatir los males venéreos. Cada repartición oficial o institución privada actuaba de forma autónoma, en función de la formación de sus médicos y de la disponibilidad de recursos para adquirir drogas específicas. En el año 1930 Pedro Baliña, titular de la Cátedra de Clínica de Dermatosifilográfica de la

10 Carrera, José Luis: “¿Debe ser regulado el empleo del título de médico especialista en enfermedades venéreas?", Revista Argentina de Dermatosifilología (en adelante RAD), tomo XIX, primera parte, Buenos Aires, junio de 1935, págs. 103-104. La cátedra de Clínica Dermatosifilográfica fue fundada en 1892 por Baldomero Sommer en el hospital San Roque que, a partir de su remodelación en 1929, pasó a llamarse Ramos Mejía. En el año 1925 el profesor Pedro Baliña asumió la titularidad de la cátedra. La asignación de recursos (100 pesos mensuales) provenía de la Universidad de Buenos Aires, a excepción del año 1929 en que le fueron otorgados del presupuesto general de la Nación 50.000 pesos, a fin de instalarse en el renovado hospital y adquirir los elementos necesarios para cumplir con sus objetivos: "La cátedra de Clínica Dermatosifilográfica de la Facultad de Ciencias Médicas de Buenos Aires durante el período 1925-1935”, RAD, tomo XX, segunda parte, 1936, págs. 191-208. 
Facultad de Ciencias Médicas, propuso un plan de tratamiento para la sífilis junto con un modelo de libreta individual para quienes fueran sometidos a su cura, con el fin de evitar el "desorden" y la "insuficiencia del tratamiento que se aplica a los pacientes, que llevan a futuros brotes del mal en un enfermo supuestamente curado y a la posibilidad de ser un agente involuntario de contagio". A pesar de que ambos fueron adoptados por la Asistencia Pública de la ciudad de Buenos Aires y por el Departamento Nacional de Higiene, muchas reparticiones quedaron al margen de lo que, en esos años, constituía la moderna sifiloterapia. ${ }^{11}$

Por último, la atención de las enfermedades venéreas era un terreno disputado por los clínicos generalistas, sobre todo en las pequeñas ciudades o en las zonas rurales que no estaban dotadas de infraestructura hospitalaria, o por especialistas tales como los urólogos, en el caso de la blenorragia, o los dermatólogos, en el caso de la sífilis. El proceso de especialización se puso en evidencia hacia finales de la década de los veinte. En el año 1927 la Sociedad Dermatológica Argentina, fundada en 1907 con sede en el Hospital Ramos Mejía, tomó el nombre de Asociación Argentina de Dermatología y Sifilografía, en función de la importancia que la sífilis ocupaba en su agenda de preocupaciones. Asociada a la cátedra de Clínica de Dermatosifilográfica de la Facultad de Ciencias Médicas fue, probablemente, la institución especializada en el estudio de patologías venéreas más respetada en el ámbito académico y en la estructura sanitaria. Desde su órgano editorial se discutían y difundían los adelantos de las investigaciones en el tratamiento de las enfermedades de contagio sexual. Su presidente entre 1927 y 1932 y titular de la cátedra entre 1925 y 1948, Pedro Baliña, fue frecuentemente consultado por las autoridades municipales y nacionales acerca de la viabilidad de las políticas proyectadas o del éxito de la puesta en práctica de numerosas disposiciones reglamentarias; su secretario entre 1927 y 1930 y vicepresidente entre 1933 y 1935, José Puente, fue nombrado jefe de la Sección Dermatovenerológica del Departamento Nacional de Higiene en el año 1936; la mayoría de los miembros de las sucesivas comisiones directivas formaron parte de los servicios de Dermatosifilogafía de los principales hospitales nacionales.

A pesar del prestigio de esta institución, la primera asociación que dio cuenta de la necesidad de autonomía de la especialidad venerológica, sepa-

11 Baliña, Pedro: "En favor de la lucha contra la sífilis en nuestro país"; "Libreta individual de tratamiento para enfermos de sífilis"; "Plan de tratamiento de la sífilis", $R A D$, tomo XIV, 1930, respectivamente págs. 70-72, 73-78 y 80-95. 
rándola de otras como la urología o la dermatología, fue la Sociedad Argentina de Venerología y Profilaxis Social. Fundada en el año 1936 como espacio de discusión y formación de los médicos de los dispensarios venerológicos de la municipalidad de Buenos Aires, fue presidida por el urólogo Leónidas Rebaudi. Uno de sus miembros definió esta nueva disciplina como la "parte de la medicina que se ocupa de las enfermedades contraídas durante el acto sexual" y que agrupa a las dolencias de su jurisdicción por su patogenia y no por una clasificación orgánica, como sucede con el resto de las especialidades. Aunque reconocía el aporte de dermatosifilógrafos y genitourólogos en el tratamiento de las enfermedades venéreas, advirtió que éstas no eran el objetivo exclusivo de tales disciplinas, razón que justificaba la existencia de una rama de la medicina específica. Por otro lado, resaltó la importancia de esta nueva especialidad desde el punto de vista social, emparentándola con otras ramas de la medicina social como la tisiología o la cancerología. Paralelamente a la búsqueda de legitimidad académica, los venerólogos lucharon por un espacio propio en la estructura de la atención sanitaria a través de la creación de servicios venerológicos donde pudiera "atenderse a los enfermos y seguirlos en el curso de su mal, hospitalizándolos", sin necesidad de recurrir a otros servicios de los sanatorios. ${ }^{12}$

Este proceso de especialización trajo como consecuencia inevitable el reclamo de reconocimiento oficial de los médicos especialistas en enfermedades venéreas, sea dermosifilógrafo o venerólogo, y el acceso a los cargos públicos por concurso probatorio de idoneidad y experiencia previa del candidato en la especialidad. Si el título público de médico dermasifilógrafo nunca fue reconocido por las autoridades universitarias, el de venerólogo fue admitido en el ámbito municipal como una carrera técnica profesional a partir del año 1935. Por su parte, el concurso de cargos públicos, que además de afirmar la identidad de cuerpo de los integrantes de la nueva especialidad, generaba mecanismos de control sobre el desempeño de los funcionarios de sanidad y pretendía alejar su designación de fines políticos, fue puesto en práctica solamente en la jurisdicción de la Capital Federal. ${ }^{13}$

12 Massolo, Orestes: "Ensayos de delimitación venerológica", Revista de la Sociedad Argentina de Venerología y Profilaxis Social (en adelante RSAVPS), Año I, n. ${ }^{\circ}$ 1, Buenos Aires, mayo de 1937, págs. 17-19.

13 Carrera, José Luis: “¿Debe ser regulado ...”, págs. 102-112, y Baliña, Pedro: “Sobre normas para concursos de médicos encargados de la asistencia y profilaxis de los enfermos de la piel, sífilis y lepra", $R A D$, tomo XIV, 1930, págs. 102-105. 


\section{La centralización de la atención de las enfermedades venéreas}

La creciente demanda de centralizar e imponer racionalidad a los desarticulados intentos de prevención y asistencia de las enfermedades venéreas se hizo evidente en los últimos años de la década de los veinte. Estas demandas provinieron fundamentalmente de los círculos médicos, para quienes resultaba indispensable procurar la asistencia a toda la población dispersa en el extenso territorio nacional y a aquella que ingresaba a través de las fronteras, unificar tratamientos y proveer a bajo costo las drogas necesarias para curar las dolencias, dichas demandas fueron también apoyadas por amplios sectores de la burocracia estatal y por buena parte de los legisladores.

Parecía existir cierto consenso en que para intervenir en la prevención y atención de una enfermedad de causas de muy variado orden, fisiológicas, "morales", sociales y económicas se requería de la injerencia de un organismo dotado de múltiples atribuciones y con cierta capacidad de represión. El Departamento Nacional de Higiene fue visualizado como la repartición dentro de la esfera estatal que podía llevar a cabo este objetivo. Dicho organismo no contaba solamente con la tutela del Ministerio del Interior, cuyos recursos materiales y simbólicos se expandían conforme crecían las atribuciones de un Estado crecientemente interventor en la regulación de la vida social y económica, sino con un grupo consolidado de funcionarios que, desde los años veinte, venían elaborando un proyecto que intentaba dar respuesta a los problemas sociales desde el ámbito de la higiene.

Mas allá de su orientación partidaria, Gregorio Aráoz Alfaro, Tiburcio Padilla y Miguel Susini, sucesivos presidentes del Departamento Nacional de Higiene entre los años 1923 y 1938, compartieron el propósito de ampliar las atribuciones del organismo que presidían. Propósito que probablemente respondía a su aspiración de colonizar la estructura burocrática del Estado en su calidad de expertos, pero que estaba justificada por un nuevo concepto de la salud. En efecto, como ha sido estudiado recientemente, dejando atrás el tono alarmista con el que se respondía a los brotes epidémicos, se articuló, hacia las primeras décadas del siglo XX, una nueva versión de la higiene que combinaba la preocupación por la salud con aquélla por la perfección física y moral de la población, presente y futura. Tan ambicioso concepto requería de la expansión de las reparticiones sani- 
tarias y, a su vez, de una profundización de su capacidad de intervención en fenómenos que eran considerados, anteriormente, como patrimonio de la esfera privada de los individuos. En este contexto el Departamento Nacional de Higiene creó nuevas dependencias como la División de Asistencia y Protección a la Maternidad y la Infancia, en 1923, o la de Profilaxis de la Lepra, Sífilis y Enfermedades Venéreas, en 1927. ${ }^{14}$

Este proyecto del Departamento Nacional de Higiene necesitaba contar con la aprobación de una ley nacional que legitimara su propuesta y lo dotara de recursos económicos. Esto fue posible en la segunda mitad de la década de los treinta cuando un conjunto de temas de fuerte impacto en la opinión pública se convirtió en argumento de presión para que el Parlamento discutiera la aprobación de una ley de profilaxis de las enfermedades venéreas. En primer lugar, la prensa se encargó de poner en evidencia la falta de control sanitario en los burdeles debido a la corrupción de funcionarios políticos y policiales, y la imposibilidad de obligar a revisiones médicas periódicas a las mujeres que ejercían la prostitución de forma clandestina. En segundo lugar, el tráfico de mujeres de Europa a Buenos Aires, destinado a alimentar los burdeles, se convirtió en objeto de una verdadera cruzada de la opinión pública, local e internacional, tras conocerse las denuncias de mujeres que habían sido obligadas a ejercer la prostitución por una de las más importantes organizaciones locales de "trata de blancas". En tercer lugar, cada vez resultaba más claro que el padecimiento de las "dolencias secretas" no involucraba solamente a las mujeres de "mala vida", sino también a todos los varones que se entregaban a los placeres del sexo e, indirectamente, a sus familias. Por último, los insistentes llamamientos de la Sociedad de las Naciones a sus países miembros para que suprimieran la prostitución reglamentada como forma de disminuir los índices de enfermedades venéreas. ${ }^{15}$

Haciéndose eco de estas demandas, los diputados Ángel Giménez, médico higienista, miembro fundador del partido Socialista, presidente de la Sociedad Luz, y Tiburcio Padilla, afiliado al Partido Demócrata Nacional y presidente del Departamento Nacional de Higiene entre los años 1928 y 1932, presentan sus proyectos de ley sobre profilaxis de enfermedades

14 Un estudio sobre el proceso de consolidación de la nueva concepción de la higiene en: Armus, Diego, y Belmartino, Susana: "Enfermedades, médicos y cultura higiénica", en Cattaruzza, Alejandro (dir.): Crisis económica, avance del estado e incertidumbre política (1930-1943), Nueva Historia Argentina, tomo 7, Editorial Sudamericana, Buenos Aires, 2001, págs. 285-287.

15 Gramático, Karin: "Obreras, prostitutas y mal venéreo....”, págs. 120-121. 
venéreas. Finalmente, una Comisión de Higiene y Asistencia Social de la Cámara Baja fue la encargada de conciliar los proyectos de estos dos legisladores de profesión médica, convirtiéndolos en ley el 17 de diciembre de 1936. Las disposiciones centrales de la normativa, que llevaba el número 12.331, fueron la prohibición del establecimiento de casas o locales donde se ejerciera la prostitución o se incitara a ella, la obligatoriedad del certificado prenupcial para los varones, la incorporación en los planes de estudio de la educación formal de la instrucción sexual, y la organización y centralización de la prevención y tratamiento de los males venéreos en todo el país. Para cumplir con este último objetivo se previó la creación, en el Departamento Nacional de Higiene, de una sección denominada Profilaxis de las Enfermedades Venéreas, a la que se le otorgaron como funciones el ejercicio de la superintendencia general y la coordinación de servicios venereológicos en hospitales, dispensarios, laboratorios, de origen nacional, provincial, municipal o particular; la distribución económica y metódica de los medicamentos y el material de propaganda y divulgación científica; el estudio médico y social de las enfermedades venéreas; la organización del servicio de asistencia social; la multiplicación en todo el país del número de los dispensarios antivenéreos que funcionaran en conexión con el servicio social; y el desarrollo de la educación sexual, directamente o por medio de las entidades a quienes correspondiera llevar a cabo esta enseñanza. ${ }^{16}$

A cargo de la Sección de Profilaxis de las Enfermedades Venéreas se nombró a José Puente — profesor adjunto de la Clínica Dermatosifilográfica de la Facultad de Ciencias Médicas, Jefe del servicio de Venerología en el hospital Muñiz, miembro de la Asociación Argentina de Dermatología y Sifilología y de la Sociedad Argentina de Venerología y Profilaxis Socialy a Milio Fernández Blanco — adjunto de la Clínica Dermatosifilográfica de la Facultad de Ciencias Médicas, médico dermatólogo de los hospitales Fernández y Ramos Mejía, y miembro de la Asociación Argentina de Dermatología y Sifilografía-. Esta designación no representó un cambio en la estructura administrativa del Departamento Nacional de Higiene puesto que ambos médicos ocupaban la jefatura de la Sección de Profilaxis de la Lepra, Sífilis y Enfermedades Venéreas creada, esta última, en 1927.

16 Véanse los proyectos en Diario de Sesiones de la Cámara de Diputados, 15 de septiembre de 1933, tomo IV, págs. 411-425; 30 de mayo de 1934, tomo I, págs. 662-663, y 1 de junio de 1935, tomo I, págs. 333-335 y el texto de la ley en: "Legislación Sanitaria", Boletín Sanitario del Departamento Nacional de Higiene (en adelante BSDNH), Año I, núms.1-12, Buenos Aires, 1937. 
La nueva sección dispuesta por la ley 12.331, que finalmente adoptó el nombre de Dermatovenerológica, comenzó a funcionar en el año 1938. Una de sus primeras actividades, ordenada por el decreto reglamentario 10.466 del 2 de abril de 1937, fue llevar a cabo una investigación preliminar acerca de cómo se realizaba la lucha antivenérea en todo el país y de qué elementos y recursos se disponía. Para ello presentaron un informe de situación los gobiernos de las provincias y territorios nacionales, la municipalidad de Buenos Aires, la Sociedad de Beneficencia, los hospitales y clínicas particulares, las sociedades de socorros mutuos y las instituciones de cualquier índole relacionadas con la profilaxis antivenérea. Según la Sección Dermatovenerologica, entre los servicios y consultorios en los hospitales y los dispensarios especializados, se contaba en 1938 con 570 centros de atención y tratamiento dispersos por todo el país. Todos ellos se ajustaban a la utilización de normas uniformes de notación y estadística y al empleo de homogéneos tratamientos para los casos generales de sífilis, lo que permitía al Departamento Nacional de Higiene disponer de una evaluación del grado de morbilidad de las afecciones venéreas y las variables de intensidad según las zonas. ${ }^{17}$

En el año 1939 el número de servicios antivenéreos ascendió a 753, uno cada 17.264 habitantes. Según la versión triunfalista del director de la Sección, esta cifra colocaba a la Argentina por encima de los esfuerzos profilácticos realizados en Estados Unidos, dónde existía un centro cada 117.000 habitantes. Basándose en la encuesta realizada el año anterior y en los datos sobre los conscriptos proporcionados por la Dirección General de Sanidad del Ejército, se intensificó la campaña de profilaxis en zonas que acusaban una mayor morbilidad o que disponían de escasos servicios. Así se crearon 17 dispensarios, en su mayoría en la región litoral (Corrientes, Chaco y Misiones) y se acentuó la actividad de las asistencias públicas, delegaciones y barracas sanitarias ya establecidas. A su vez, las provincias adaptaron y crearon nuevos servicios y dispensarios en sus respectivas jurisdicciones. Sin embargo, la respuesta de los gobiernos locales a los esfuerzos del Departamento Nacional de Higiene por centralizar la profilaxis venérea no fue, al menos en los primeros años que siguieron a la sanción de la ley 12.331, tan unánime como se esperaba. Mientras que las provincias de Buenos Aires, Santa Fe, Entre Ríos, Córdoba, Mendoza,

17 "Legislación Sanitaria", BSDNH, Año I, 1937, págs. 402-406 e "Informe de la Sección Dermatovenerológica del año 1938”, BSDNH, Suplemento 1, mayo de 1939, págs. 238-239. 
Tucumán, Salta, Jujuy y San Luis respondieron positivamente a las directivas de la Sección Dermatovenerológica; y San Juan, Santiago del Estero y Catamarca lo hicieron de forma deficiente; Corrientes desoyó cada una de las propuestas y pedidos provenientes de la repartición de jurisdicción nacional. ${ }^{18}$

Los años siguientes parecen haber estado marcados por una creciente colaboración de las instituciones bajo la jurisdicción de distintos niveles de gobierno y de la órbita privada con la Sección Dermatovenerológica. Esta supuesta sumisión a la administración central puede explicarse por la función exclusiva del Departamento Nacional de Higiene de distribuir económica y metódicamente los medicamentos, por él recomendados para seguir los tratamientos, a todos los dispensarios antivenéreos de orden público o privado, incluidos los institutos penales. Las drogas, liberadas de todo impuesto aduanero en caso de importación y de impuestos internos en caso de fabricación, eran adquiridas por las autoridades sanitarias centrales con su propio presupuesto. Así, por ejemplo, en 1939 el Departamento Nacional de Higiene compró grandes partidas de medicamentos arsenicales a Alemania, Francia y Estados Unidos y promovió la fabricación de mercuriales, bismutales y antimoniales en los Institutos de Química y Bacteriológico. Una vez declarada la guerra, las drogas arsenicales se compraron en Canadá y Estados Unidos, a muy alto precio, y se intensificó la producción nacional de las restantes. Esta triple prerrogativa del Departamento de imponer un tratamiento estandarizado para las enfermedades venéreas, decidir acerca de aquellos medicamentos que debían ser liberados de las obligaciones impositivas y distribuirlos en todo el país, le confirió la capacidad de centralizar la lucha antivenérea y la obtención de razonables resultados. ${ }^{19}$

Junto con la responsabilidad de organizar y centralizar el tratamiento de las enfermedades venéreas, la Sección Dermatovenerológica debía encargarse de proyectar la acción preventiva de estas dolencias, operada por la educación sexual y por la divulgación de los principios de profilaxis individual. Probablemente el primero de estos objetivos, por los prejuicios

18 Puente, José: "Estado actual de la profilaxis de las enfermedades venéreas en la República Argentina", BSDNH, Año IV, mayo-agosto de 1940, págs. 426-427.

19 Ibídem, págs. 427-428; BSDNH, Año V, núms. 1-2-3, enero-marzo de 1941, pág. 45; Año VI, núms. 5-6-7, abril-junio de 1942, pág. 226 y Año VII, núms. 1-2-3, enero-marzo de 1943, págs. 62 63. Una crítica a la falta de presupuesto para la producción local de arsenobenzoles y a los problemas de suministro ocasionados por la guerra en: Baliña, Pedro: "El problema venéreo al cumplir cinco años de vigencia la ley nacional de profilaxis n. ${ }^{\circ} 12.331$ ”, RAD, tomo XXVI, cuarta parte, 1942, pág. 761. 
morales que conlleva, fue el más difícil de poner en práctica. En 1938 una comisión del Círculo Médico de Córdoba publicó los resultados de una encuesta realizada entre las autoridades sanitarias de los tres niveles de gobierno (civiles y militares) y médicos y legisladores que hubiesen tenido destacada participación en los debates parlamentarios que precedieron a la sanción de la ley, con el fin de evaluar la mejor forma de llevar a cabo la nueva normativa. Respecto a la educación sexual, si bien la mayoría estaba de acuerdo con su importancia, se sugirió que se encargara esta tarea a médicos o a educadores especialmente preparados. Mientras que en los grados elementales sólo bastaba con que los maestros no presentaran "la función sexual como inmoral" a fin de evitar la futura "sexofobia" o el "homosexualismo", en los grados superiores se recomendó proporcionar información gradual acerca de la función reproductiva de las plantas, de los animales y, por último, del hombre. Esta explicación biológica debía estar acompañada por la enseñanza del "valor de la castidad y la continencia" que, lejos de producir algún daño, eran "recomendables desde el punto de vista médico e higiénico". ${ }^{20}$

Probablemente como consecuencia de la influencia de este tipo de opiniones en la puesta en práctica del texto de la ley, que provenían del campo de la medicina, de los funcionarios de distintos ministerios, del mundo de la política, en consonancia con los criterios sostenidos por la Iglesia Católica, de creciente influencia en los debates públicos, el Departamento Nacional de Higiene sólo logró imponer los contenidos de educación sexual en el currículo de materias como Biología, Anatomía, Fisiología e Higiene de los colegios nacionales dependientes del Ministerio de Justicia e Instrucción Pública, previo acuerdo con esta repartición. ${ }^{21}$

Paralelamente a la educación sexual, la Sección Dermatovenerológica era la encargada de difundir los principios básicos de profilaxis individual y proveer los elementos necesarios para ponerla en práctica. Para cumplir con el primer objetivo organizó conferencias populares, proyecciones cinematográficas, propaganda gráfica en las calles y distribución de folletos informativos y, a partir del año 1942, inauguró el Museo de Venerología.22

20 Tey, Antenor; Garzón, Rafael, y Brandan, Gustavo: "Informe presentado por la subcomisión del Círculo Médico de Córdoba (A propósito de la ley 12.331 de profilaxis de las enfermedades venéreas)", $R A D$, tomo XXII, segunda parte, 1938, págs. 168-172.

21 Puente, José: "Estado actual de la profilaxis ...", págs. 429-430.

22 BSDNH, Año V, núms. 1-2-3, enero-marzo de 1941, pág. 44; Año VI, núms. 4-5-6, abriljunio de 1942, págs. 228-229 y Año VII, núms. 1-2-3, enero-marzo de 1943, págs. 64-65. 
Para llevar a cabo el segundo, la ley 12.331 establecía en su artículo sexto que el Departamento Nacional de Higiene debía determinar los lugares de venta obligatoria de equipos preventivos para profilaxis individual venérea. Aunque en el año 1940 José Puente informó acerca de que la Sección de la que era responsable poseía un pequeño stock de estos equipos (jabón, pomada profiláctica y un prospecto con instrucciones), que "se ampliará con nuevas adquisiciones, para proceder a su distribución de la manera más amplia y eficaz", las sucesivas memorias no hicieron mención del cumplimiento de este compromiso. ${ }^{23}$

Por su parte, los médicos responsables de los dispensarios antivenéreos de la Capital Federal insistieron en que "no basta solamente con ilustrar al vulgo; es necesario facilitarle los medios adecuados y poner al alcance los elementos indispensables para que pueda practicarla correctamente". Para ello propusieron la instalación, en todos los hospitales municipales, nacionales o particulares, de un gabinete profiláctico mixto, convenientemente ubicado (anexo a la guardia, por ejemplo), para que aquella persona que sospechara haber estado en contacto con un agente de infección pudiera asearse debidamente. El gabinete debía contar con todos los elementos necesarios (lavatorios, mingitorios, soluciones antisépticas para el lavado, pomadas, carteles informando sobre los peligros del contagio venéreo e instrucciones de cómo realizar la profilaxis) y horario continuo de funcionamiento, sobre todo por la noche..$^{24}$

La discusión sobre la necesidad de incluir el Servicio Social como agente de la profilaxis contra las enfermedades venéreas se instaló durante los años posteriores a la promulgación de la ley 12.331. Según los especialistas, después del diagnóstico, análisis y tratamiento gratuito de un mal venéreo era necesario persuadir al enfermo de que debía cumplir hasta el final con el tratamiento asignado. Debido a este último objetivo el Servicio Social, a cargo de visitadores especiales formados por el Estado, justificaba su existencia. A esta tarea se le sumaban la búsqueda de personas contaminadas y contaminantes y su persuasión de la necesidad de iniciar un tratamiento, la educación del enfermo, la confección de su ficha individual y familiar a fin de elaborar estadísticas y su control médico social. ${ }^{25}$

23 Puente, José: "Estado actual de la profilaxis ...", pág. 433.

24 Russo, Francisco: "Profilaxis individual", RSAVPS, Año I, tomo I, n. 1, mayo de 1937 , págs. 99-100.

25 Fisina, Miguel: "El servicio social en los dispensarios antivenéreos", RSAVPS, Año I, tomo I, n. ${ }^{\circ}$, diciembre de 1937, págs. 133-137, y Cremona, Roberto: "La necesidad urgente de creación del servicio social en los dispensarios antivenéreos”, RSAVPS, Año II, tomo I, n. ${ }^{\circ}$ 4, mayo 1939, págs. 331-333. 
Otro de los instrumentos de profilaxis venérea impuesto por la ley 12.331 fue el examen médico prenupcial gratuito y obligatorio para los varones, que inhabilitaba para contraer matrimonio a las personas afectadas por enfermedades venéreas durante el período de contagio. Según el decreto reglamentario de la ley, el examen podría ser realizado por los directores o jefes de servicio de cualquier especialidad de la medicina de hospitales nacionales, provinciales, municipales o particulares; por los médicos de Sanidad Militar y Naval y los de Policía de cualquier localidad; por los médicos facultados para ese objeto por el Departamento Nacional de Higiene y por los médicos particulares, cuando dentro de su jurisdicción no existiera médico diplomado con cargo oficial o expresamente autorizado. En las memorias anuales de la Sección Dermatovenerológica tres parecen ser las preocupaciones de las autoridades nacionales respecto al examen prenupcial. En primer lugar, su aceptación por parte de la población en general. Según los informes, no existía la resistencia supuesta antes de llevar a la práctica la ley y la opinión pública parecía consensuar el "valor sanitario y moral implícito en esta medida". En segundo lugar, la reducción de matrimonios y el incremento de nacimientos "ilegítimos", temores que fueron desmentidos por las cifras estadísticas presentadas por el Departamento Nacional de Higiene. Por último, la dificultad de realizar los análisis serológicos en lugares que no poseían laboratorios o que estaban muy alejados de ellos. Con este fin la Sección Dermatovenerológica realizó gestiones ante la Dirección General de Correos y Telégrafos para remitir gratuitamente por vía aérea, desde zonas alejadas, las extracciones a ser analizadas por el Instituto Bacteriológico Nacional. Por otro lado, se proyectó la creación, hasta el año 1942 sin resolución práctica, de laboratorios regionales ubicados en lugares estratégicos del territorio destinados a servir a sus respectivas zonas de influencia. ${ }^{26}$

A pesar del optimismo de los informes del Departamento Nacional de Higiene, los límites de la normativa referida al certificado prenupcial fueron advertidos desde los círculos médicos y legales. Desde el punto de vista médico, se sugirió que para evitar la entrega de certificados después de un examen clínico o de reacciones sanguíneas insuficientes era menester estandarizar el proceso que debían seguir los diagnósticos y ajustarlo a los

26 BSDNH, Suplemento 1, mayo de 1939, págs. 239-241; Año IV, n. ${ }^{\circ}$ 1, enero de 1940, págs. 16-17; Año V, núms. 1-2-3, enero-marzo de 1941, págs. 41-43, Año VI, núms. 4-5-6, abril-junio de 1942, pág. 227-228 y Año VII, núms. 1-2-3, enero-marzo de 1943, págs. 63-64. 
nuevos conocimientos de la disciplina venerológica. ${ }^{27}$ En este sentido, Francisco Russo propuso que se modificara el texto de la ley disponiendo la creación de consultorios ad hoc para practicar los exámenes prenupciales, reglamentando cómo debían realizarse (análisis serológicos y bacteriológicos de rigor llevados a cabo en laboratorios oficiales) y documentando para cada sexo y estado civil sus resultados..$^{28}$

Desde el punto de vista legal, Enrique Díaz de Guijarro, profesor de derecho civil en la Facultad de Ciencias Económicas de la Universidad de Buenos Aires, evidenció la arbitrariedad de imponer la obligatoriedad del certificado prenupcial a los varones, cuando la transmisión de las enfermedades era posible tanto por vía masculina como femenina. El argumento se reforzaba, para este médico legista, ante los enlaces de mujeres viudas o divorciadas en cuyo caso "no es posible esgrimir el efectista pero inocuo argumento de que el examen prenupcial es un agravio a la honestidad de la mujer". Esta posición, sostenida también por un importante número de médicos ligados a la asistencia venerológica que, en 1938, coincidieron por medio de la realización de una encuesta en la necesidad de extender a las mujeres la obligación del certificado prenupcial o, al menos, de una declaración jurada de buena salud, encontró una opinión desfavorable por parte del Departamento Nacional de Higiene. Marcial Quiroga, médico de la Sección Dermatovenerológica, sugirió que en los casos de contagio conyugal y transmisión a la descendencia la infección provenía generalmente del hombre. ${ }^{29}$

Un último aspecto legislado por la norma de profilaxis antivenérea fue la prohibición, en toda la República, del establecimiento de casas o locales donde se ejerciera la prostitución o se incitara a ella. Esta medida abolicionista fue apoyada por el Departamento Nacional de Higiene tanto como una forma de frenar la difusión de las enfermedades venéreas, como de evitar la "perversión moral" y la "delincuencia" propiciada por los lugares donde fuera ejercida la "mala vida". Aunque sus autoridades reconocían que la prostitución "es un fenómeno social que no podrá hacerse desaparecer com-

27 Massolo, Orestes: "Al margen del certificado médico prenupcial", RSAVPS, Año I, tomo I, n. ${ }^{\circ}$ 2, 1937, págs. $151-154$.

28 Russo, Francisco: "La reforma de la ley 12.331", RSAVPS, Año V, tomo V, n. ${ }^{\circ}$ 8, agosto de 1942, págs. 839-844.

29 Díaz de Guijarro, Enrique: "Eugenesia y Matrimonio", Revista de Medicina Cancerología, Año XIII, n. ${ }^{\circ}$ 130, Buenos Aires, 1939, págs. 20-26; Tey, Antenor; Garzón, Rafael, y Brandan, Gustavo: "Informe presentado ...", pág. 175, y Quiroga, Marcial: "Certificado Prenupcial”, BSDNH, Año 1941, págs. 759-761. 
pletamente, pero sí atenuar su extensión", su paso a la clandestinidad era interpretado como un medio de superación del régimen "reglamentarista" ${ }^{30}$

A pesar de que la mayor parte de la comunidad médica estaba de acuerdo con la adopción del sistema abolicionista, el ejercicio clandestino de la prostitución resultante, exento de la obligación de la visita médica obligatoria, era visto como un nuevo peligro para la propagación de las enfermedades venéreas. De ahí que se propusiera con insistencia la adopción obligatoria de la libreta de salud por parte de toda mujer que se trabajara en un "cabaret", "boite", "dancing" o "cafetín", a fin de supervisar su salud periódicamente, y el control de la prostitución masculina cuyos códigos y prácticas resultaban aún desconocidas. Por otro lado, se sugería la organización de un cuerpo de Policía Sanitaria, encargado de vigilar a todas las personas que por su profesión (bailarinas, nodrizas, servicio doméstico, mozos) o modo de vida (prostitutas) pudieran constituir un "peligro social" en caso de estar infectadas. ${ }^{31}$

Más allá de los límites señalados a la ley 12.331 por sus contemporáneos, la centralización de la lucha contra las enfermedades venéreas comenzó a dar resultados positivos hacia finales de la década de los treinta. Las cifras proporcionadas por la Sección Dermatovenerológica muestran la paulatina disminución del contagio venéreo, en especial de la sífilis y la blenorragia. Estos datos fueron confirmados por la Asociación Argentina de Dermatología y Sifilología, aduciendo sus razones al seguimiento del plan de tratamiento de la sífilis y al uso de la libreta individual para los pacientes que la sufrían, ambos recomendados por la asociación; a la provisión abundante y gratuita, por parte del Estado, para todo el país, de compuestos arsenicales y bismutales; a la multiplicación de servicios antivenéreos, sobre todo en los centros urbanos de población más densa; a la implementación del certificado prenupcial obligatorio y al cierre de los prostíbulos. ${ }^{32}$

30 Puente, José: "Estado actual de la profilaxis...", pág. 442.

31 Baliña, Pedro: "Libreta de salud, obligatoria, y lucha antivenérea", $R A D$, tomo XXI, tercera parte, 1937, págs. 611-622; Russo, Francisco: "Profilaxis en los cafetines", RSAVPS, Año I, tomo I, n. ${ }^{\circ}$, mayo de 1937, págs. 95-97; Panizza, Ismael: "Una omisión de la Ley de Profilaxis Venérea", RSAVPS, Año I, tomo I, n. ${ }^{\circ} 1$, mayo de 1937, págs. 101-102 y Landaburu, Laureano, y Aftalion, Enrique: "Aspectos civiles, penales y administrativos de la ley 12.331 de profilaxis antivenérea", $R A D$, tomo XXVI, cuarta parte, 1942, pág. 771.

32 BSDNH, Año V, núms. 1-2-3, enero-marzo de 1941, pág. 22, Año VI, núms. 4-5-6, abriljunio de 1942, pág. 41 y Año VII, núms. 1-2-3, enero-marzo de 1943, pág. 63, y Baliña, Pedro: "Resultados generales del tratamiento y la lucha contra la sífilis en la Argentina", RAD, tomo XXVI, primera parte, 1942, págs. 55-64. 


\section{Hacia un modelo más represivo de profilaxis de las enfermedades venéreas}

A los pocos años de legislado, el sistema abolicionista comenzó a ser criticado, desde el punto de vista moral y sanitario, en los ámbitos médico y legal. El cierre de los burdeles ponía en evidencia lo inevitable del ejercicio de la prostitución, visualizada a través de la clandestinidad de esta práctica $\mathrm{y}$, a su vez, los beneficios secundarios que de todos modos traía. Un importante número de académicos, administradores, políticos y militares empezó a sospechar que la persecución de las mujeres que ejercían la prostitución favorecía indirectamente, al "trabar las posibilidades de normal expansión sexual de una juventud vigorosa y precoz", el incremento de una serie de manifestaciones de "patología individual y social", siempre latentes, como la homosexualidad, el onanismo, el bestialismo, los trastornos neuróticos, las relaciones incestuosas, los delitos sexuales, las prácticas abortivas y los nacimientos ilegítimos. ${ }^{33}$

Para evitar la expansión de estos "males" la Comisión Honoraria Consultiva de Profilaxis Venérea, integrada por prestigiosos especialistas sobre la materia, sugirió que el criterio abolicionista que inspiraba la ley no prohibía la prostitución, sino el prostíbulo y que a la mujer que ejercía esta actividad en su casa, sola e independiente de proxeneta alguno, no debía imponérsele pena alguna. Por otro lado, proponía que en los sitios alejados del país, donde había grandes núcleos de hombres solos cumpliendo con el servicio militar, en lugar de autorizarse la instalación de "casas de tolerancia", debería estimularse la radicación de mujeres que "actúen y vivan dispersas, aisladas unas de otras, sometidas a frecuentes revisaciones médicas". ${ }^{34}$

El sonado episodio de los cadetes del Colegio Militar de la Nación, quienes fueron descubiertos en reuniones de la cultura gay y fotografiados desnudos en poses sugestivas generó una suerte de "pánico moral" que operó como acicate para modificar la ley 12.331 en los aspectos concernientes a la prostitución. La Dirección Nacional de Salud Pública y Asistencia Social, a cargo de Eugenio Galli, ex director de Sanidad Militar y ferviente impulsor de la profilaxis venérea en el ámbito castrense, pro-

33 Landaburu, Laureano, y Aftalion, Enrique: "Aspectos civiles...”, págs. 767-768 y 771.

34 Baliña, Pedro; Castaño, Enrique; Zwanck, Alberto, y Scolari, Pedro: "Apreciaciones emitidas sobre profilaxis venérea", $R A D$, tomo XXVIII, n. ${ }^{\circ}$ 2, junio de 1944, págs. 178-179. 
yectó el decreto rectificatorio de dicha ley. ${ }^{35}$ La nueva normativa, aprobada en abril de 1944, dispuso, por un lado, el establecimiento excepcional de casas de tolerancia cuyo funcionamiento fuera autorizado por la Dirección Nacional de Salud Pública y Asistencia Social y por el Ministerio del Interior. Dicho consentimiento se otorgaba atendiendo a necesidades locales, en general, proporcionar entretenimiento femenino sometido a control sanitario a los soldados y conscriptos, limitando su vigencia al tiempo que las mismas subsistieran. Por otro lado, el simple ejercicio de la prostitución por la mujer en su casa, de forma individual o independiente, sin afectar al pudor público, no constituía delito para esta nueva normativa. Por último, si bien los administradores de casas de tolerancia seguían siendo penados, quedaban exentas de castigo las mujeres que regentearan o trabajaran en los burdeles habilitados bajo las condiciones establecidas por el decreto. ${ }^{36}$

Los venerólogos de la Capital Federal no tardaron en hacer objeciones a estas nuevas disposiciones, alegando que la reagrupación de prostitutas en nuevos burdeles autorizados y la oficialización de su actividad clandestina en la medida que no eran penadas por ejercerla, constituían un peligro para el recrudecimiento de las enfermedades venéreas. De ahí que propusieran un severo control sanitario en las casas de tolerancia a fin de evitar que se convirtieran en los "mayores focos de diseminación de las enfermedades sifilítico-venéreas". No obstante, el peso de su opinión fue bastante marginal puesto que la Dependencia de Profilaxis Venérea de la Asistencia Pública de Buenos Aires, en conflicto con la Dirección Nacional de Salud Pública y Asistencia Social por resistirse a sus esfuerzos de centralización, no fue tenida en cuenta para integrar la comisión nacional de asesoramiento para la reglamentación del nuevo decreto. ${ }^{37}$

35 El Departamento Nacional de Higiene se convierte en Dirección Nacional de Salud Pública y Asistencia Social en agosto de 1943. Por medio del decreto 12.311 se le otorgan las facultades de centralizar, organizar y supervisar todo lo relativo a beneficencia, asilos, asistencia social, sanidad e higiene. Su director será Eugenio Galli, profesor de la Facultad de Medicina de la Universidad de Buenos Aires y uno de los más importantes impulsores de la centralización institucional de la gestión de la higiene y la asistencia social. En agosto de 1944, tras ser transformada por decreto la Dirección Nacional de Salud Pública en Dirección General y al pasar el organismo de Asistencia Social a la órbita de la Secretaría de Trabajo y Previsión, Galli renuncia a su cargo y es sucedido por Manuel Viera. Véase Veronelli, Juan Carlos, y Veronelli Correch, Magali: Los orígenes institucionales de la Salud Pública en la Argentina, Organización Panamericana de la Salud, Buenos Aires 2004, tomo II, pág. 476.

36 El episodio de los cadetes del Colegio Militar narrado por Bazán, Osvaldo: Historia de la homosexualidad en la Argentina. De la Conquista de América al siglo XXI, Marea, Buenos Aires, 2004, pág. 276.

37 Russo, Francisco: "El problema de la profilaxis de la sífilis", RSAVPS, Año VII, tomo VII, n. ${ }^{\circ} 12$, junio de 1944, págs.12-15 y "Los artículos 15 y 17, modificados de la ley 12.331", RSAVPS, Año VIII, tomo VIII, núms. 14-15, diciembre 1944-marzo 1945, págs. 21-25. 
Cabe aclarar que, a pesar de la polémica del cuerpo médico con estos cambios normativos, el optimismo acerca del éxito de las disposiciones de la ley 12.331 en la cruzada oficial contra las afecciones venéreas comenzó a desvanecerse en los primeros años de la década de los cuarenta. Las autoridades sanitarias constataron, a través de sus registros estadísticos, un ostensible aumento de casos de sífilis primaria y secundaria a partir del año 1942. Mientras que la Sección Dermatovenerológica del Departamento Nacional de Higiene, al frente de Fernández Blanco tras la muerte de José Puente, centró su explicación en el avance de la práctica clandestina de la prostitución, al margen de todo control médico; la Comisión Honoraria Consultiva de Profilaxis Venérea adjudicó este incremento a la escasez de drogas específicas suministradas por el Departamento Nacional de Higiene a numerosas reparticiones públicas y privadas, una vez acaecidas las restricciones comerciales durante la Segunda Guerra Mundial. ${ }^{38}$

Los médicos de los dispensarios antivenéreos de la ciudad de Buenos Aires, donde los índices de nuevos casos de enfermedades venéreas eran mucho más elevados que en el resto del país, se mostraron especialmente preocupados por esta reducción del suministro de medicamentos, cuya consecuencia más inmediata fue la suspensión de los tratamientos. Más allá de las limitaciones a la importación de drogas específicas durante el conflicto bélico, el problema de la escasez de remedios en la ciudad de Buenos Aires parece encontrar, al menos, dos explicaciones. Por un lado, el tiempo que exigían las licitaciones y los trámites burocráticos para la compra de suministros que hacían que los "proveedores, si la demanda abunda, prefieran negociar con particulares". Por otro lado, la nueva política impulsada desde la Dirección General de Salud Pública y Asistencia Social, al frente de Eugenio Galli, de no proveer medicamentos a los municipios "ricos". ${ }^{39}$

Una vez identificadas las causas del rebrote de enfermedades venéreas, los especialistas volvieron a insistir en la necesidad de implantar la libreta de salud y los exámenes periódicos para toda mujer que trabajara en "cabarets", "dancings" o "boites", dar cumplimiento al tratamiento obligatorio de los enfermos, internar a los pacientes durante el período de máxi-

38 BSDNH, Año VII, núms. 1-2-3, enero-marzo de 1943, pág. 63 y Baliña, Pedro; Castaño, Enrique; Zwanck, Alberto, y Scolari, Pedro: "Apreciaciones emitidas sobre profilaxis venérea...", pág.176.

39 Russo, Francisco: "El problema...", págs. 8-9; y Baliña, Pedro: "Incremento de la sífilis reciente. Perspectivas desfavorables. Información suministrada a las autoridades sanitarias", $R A D$, tomo XXIX, n. ${ }^{\circ} 1$, mayo de 1945, págs. 107-112. 
mo contagio, instalar gabinetes para la profilaxis individual y "equipos preventivos" en lugares públicos y organizar definitivamente el Servicio Social en las instituciones sanitarias que se ocuparan de la profilaxis venérea. Uno de los reclamos más novedoso fue el de establecer la obligatoriedad de someterse a examen clínico, ginecológico y serobactereológico a toda persona detenida por "escándalo público". Con ello se esperaba individualizar a los portadores del mal venéreo, sistematizar la información acerca de los enfermos y aislarlos en caso de que hiciera falta. La Dirección Nacional de Salud Pública realizó dichos exámenes contando, durante el año 1943, con autorizaciones para casos puntuales del Poder Judicial y amparándose, a partir de noviembre de 1944, en un inciso del artículo tercero del decreto 31.589 que la autorizaba a tomar las medidas que considerara necesarias cuando comprobara la existencia de focos epidemológicos. ${ }^{40}$

Una vez llegado al poder, el peronismo respondió enérgicamente al recrudecimiento de las enfermedades venéreas en todo el país, explicado oficialmente por la "falta de instrumentos legales y técnicos que permitan una vigilancia más precisa y una exacta ubicación de los focos por parte de la autoridad sanitaria", con la modificación y complementación de la reglamentación de la ley 12.331. En la Comisión Asesora, que proyectó las modificaciones a la normativa hasta ese momento vigente, intervinieron activamente los miembros de la Asociación Argentina de Venerología y Profilaxis Social. Esta participación, y el reconocimiento oficial de la disciplina que los situaba como especialidad de la Medicina a través del decreto 37.156, puede ser explicada por la cercanía de su secretario, Alejandro Dicovsky, a Ramón Carrillo, titular de la cartera sanitaria desde mayo de $1946 .{ }^{41}$

De las deliberaciones de dicha Comisión surgió el decreto 9.863 firmado en septiembre de 1946. Este decreto estableció que las enfermedades venéreas serían tratadas con el mismo criterio sanitario que cualquier otra

40 En mayo de 1946 la Dirección General de Salud Pública se convierte en Secretaría de Salud Pública. Cremona, Roberto: "Exposición de conceptos sobre la campaña profiláctica antivenérea: nota al Señor Interventor de Profilaxis Venérea", RSAVPS, Año VII, tomo VII, n. ${ }^{\circ} 12$, junio de 1944, págs. 99-100; Russo, Francisco: "Un agregado indispensable al decreto reglamentario de la ley 12.331" y "Equipos preventivos y secciones de instrucción profiláctica de la ley 12.331", RSAVPS, Año VII, tomo VII, n. ${ }^{\circ}$ 13, septiembre de 1944, págs. 17-32; y Garfunkel, Alfredo: "Lucha antivenérea. Algunas sugestiones", RSAVPS, Año IX, tomo IX, núms. 16-17, junio 1945-junio 1946, págs. 73-79. El decreto mencionado en: Diario de Sesiones de la Cámara de Senadores, Año 1946, tomo VII, págs. 220-221.

41 "Reglamentó el Poder Ejecutivo la ley de Profilaxis Social” y "La Venerología, especialidad de la Medicina" ambas en: RSAVPS, Año X, tomo X, n. ${ }^{\circ} 18$, diciembre de 1946, págs. 48 y $45-46$. 
afección infectocontagiosa, y sometidos los pacientes a las medidas generales que se adoptaban con todas las enfermedades transmisibles de acuerdo con la ley 12.317. Los instrumentos previstos para luchar contra estos males fueron la educación sanitaria, destacando las ventajas de la profilaxis individual; la denuncia y tratamiento obligatorios de los enfermos; la investigación de la fuente de contagio (en especial las prostitutas); la creación de un Instituto de Higiene Social para internar a los pacientes; penas específicas para todos aquellos que ignoraran la ley, incluidos los médicos, y la fundación de nuevas dependencias para reunir estadísticas, para controlar el cumplimiento de la ley (policía sanitaria) y para formar al personal técnico especializado (investigadores sociales y venerólogos). Los costos de los nuevos servicios serían financiados por los impuestos obtenidos de los casinos de Mar del Plata, Miramar y Necochea. ${ }^{42}$

Este sesgo más represivo en la lucha oficial antivenérea fue consensuado por la comunidad médica. En el año 1947 Alejandro Discovsky, partiendo de un diagnóstico en el que presentaba índices diferenciales de morbilidad venérea en las distintas regiones del país, más importantes en las que estaban situadas en los contornos del mapa que en las mediterráneas, propuso el control sanitario de las fronteras terrestres y los puertos ultramarinos y fluviales, especialmente sensibles a la reapertura del flujo inmigratorio, una vez finalizado el conflicto bélico mundial. Finalmente, la Secretaría de Salud Pública organizó lentamente esta fiscalización fronteriza estableciendo estaciones sanitarias en Pocitos, La Quiaca, Scompa, Clorinda, Paso de los Libres, y centros de higiene social en Buenos Aires y Rosario. Además suscribió convenios de profilaxis y control de las enfermedades venéreas con otros países americanos. ${ }^{43}$

Por su parte, Eduardo Glantz y Héctor González, médicos del Hospital San Roque de la ciudad de Mendoza, propusieron en las Primeras Jornadas Venerológicas Argentinas, realizadas en Buenos Aires en noviembre de 1946, la creación de un registro serosifilográfico nacional a fin de descubrir las enfermedades venéreas llamadas "encubiertas", por ser ignoradas por las personas que las padecían. Sugirieron que los exámenes fueran obligatorios para los conscriptos, los miembros de las fuerzas arma-

42 "Reglamentó el Poder Ejecutivo la ley de Profilaxis Social”, Ibídem, págs. 47-56.

43 Discovsky, Alejandro: "Plan de saneamiento venéreo: Capítulo inicial", Archivos de la Secretaría de Salud Pública de la Nación (en adelante ASSPN), tomo I, n. ${ }^{\circ}$ 2, Buenos Aires, enero de 1947, págs. 39-41, y "El problema de la prostitución”, ASSPN, vol. IV, n. ${ }^{\circ}$ 5, noviembre de 1948, pág. 423. 
das, la gendarmería y la policía; los empleados del Estado en todos sus niveles; los enfermos internados en los hospitales o concurrentes a sus consultorios externos, y optativos para el resto de la población. ${ }^{44}$

La Secretaría de Salud Pública incluyó como prioritaria en su agenda la lucha contra los males venéreos. Partiendo de cifras bastante altas de "casos nuevos" por año, 47.400 de sífilis y 30.200 de blenorragia, propuso en el Plan Analítico de Salud Pública para los primeros cinco años de gestión de esta repartición una serie de medidas entre las que se encontraban el examen prenupcial voluntario, para varones y mujeres, como "gesto patriótico"; la organización de una campaña de educación pública de gran alcance; la instalación de centros de higiene social en todo el país; el tratamiento masivo, teniendo en cuenta los adelantos de la medicina que permitían la cura a través de la penicilina, y la prevención de la prostitución a través de la creación de reformatorios y asilos para quienes ya desempeñaban esta actividad y la protección de menores en riesgo de ejercerla. Junto con estas medidas propuso una serie de proyectos legislativos: el que procuraba convertir la transmisión de las enfermedades venéreas en un delito, doloso o culposo según la conciencia del padecimiento de la infección; el que sugería la creación de un impuesto sanitario a los "dancings" y "cabarets"; el que proponía la extensión de los exámenes prenupciales a las mujeres, y el que formulaba la reapertura de los burdeles a nivel nacional, donde prostitutas y clientes serían examinados periódicamente. ${ }^{45}$

Más allá de estos proyectos y previsiones, la Dirección de Higiene Social organizó su labor alrededor de dos ejes: la educación sanitaria y la implementación de un nuevo tratamiento para las enfermedades venéreas. Para cumplir con el primero de ellos realizó previamente un conjunto de encuestas, en fábricas, colegios, dependencias de la policía y del ejército, a fin de conocer la "información que posee el pueblo en general sobre esta enfermedad social". Tras concluir que los sectores populares no contaban con un lugar donde "pedir consejo o solicitar ayuda", realizó actos de divulgación sanitaria en talleres, escuelas para adultos, dependencias de la Policía Federal, institutos militares y regimientos donde, además, se repartieron afiches, folletos, nóminas de centros de Higiene Social y se

44 Glantz, David, y González, Héctor: "El registro sero-sifilo-gráfico de la Nación”, RSAVPS, Año XII, n. ${ }^{\circ} 21$, diciembre de 1948, págs. 43-51

45 Secretaría de Salud Pública, Plan Analítico de Salud Pública, tomo II, Buenos Aires, 1947, págs. 979-1018. 
proyectaron películas. Según los médicos que la organizaron, el objetivo de la campaña era destruir el concepto de "enfermedad vergonzante"; asegurar la durabilidad de los tratamientos, una vez iniciados; recomendar métodos de prevención personal, físicos y químicos; aconsejar el matrimonio temprano; advertir acerca de los peligros de la masturbación y el proxenetismo y aclarar que la continencia sexual no era perjudicial para la salud. ${ }^{46}$

El segundo eje alrededor del cual se organizó la profilaxis antivenérea fue la implementación de un nuevo tratamiento para la sífilis basado en el suministro de penicilina, arsénico y bismuto. Según la Dirección de Higiene Social, la combinación de estas drogas limitaba enormemente en el tiempo el período del tratamiento. El único requisito para su éxito era la provisión continuada de medicamentos a todos los servicios de carácter nacional, provincial, municipal y privado. ${ }^{47}$

El gobierno peronista cumplió con el abastecimiento adecuado de dichas drogas, en especial de penicilina cuya disponibilidad dependía del mercado externo, a través del otorgamiento del monopolio de su producción a la firma norteamericana Squibb, en el año 1947. La fábrica abrió sus puertas en 1949, produciendo 51.000 unidades anuales, casi el doble de la cantidad mínima establecida por el contrato. Gracias a ello, después de 1949 fue posible expandir el control de los males venéreos de forma nueva y significativa..$^{48}$

La posibilidad de contar con material estadístico homogéneo para seguir el desarrollo de las enfermedades sociales comenzó a materializarse hacia mediados de la década peronista. Según lo dispuesto por el decreto 17.156 del año 1946, el Registro Nacional de Higiene Social se confeccionaría a partir de los datos contenidos en las fichas-denuncia de los nuevos casos venéreos, elaboradas de forma obligatoria por todos los médicos del país. Hacia finales de 1948 la Dirección de Higiene Social ya contaba con estadísticas parciales, elaboradas con estas fichas, que daban cuenta de un ascenso de los índices en las provincias del litoral,

46 Camaño, Óscar, y Rígoli, Juan: "Educación sanitaria. Su organización en la Dirección de Higiene Social de la Secretaría de Salud Pública de la Nación”, ASSPN, vol. IV, n. ${ }^{\circ}$, noviembre de 1948, págs. 461-476.

47 "Actividades técnicas de la Dirección de Higiene Social durante el mes de octubre de 1948", Ibídem, pág. 479 .

48 Ibídem, págs. 123-151. Pfeiffer, Ana, y Campins, Mónica: "La producción de medicamentos durante el peronismo y el conflicto con los laboratorios Massone. ¿Problema tecnológico o político?", Ciclos, Año XIX, vol. XIV, Buenos Aires, primer semestre de 2004, págs. 123-151. 
como consecuencia del éxodo de población desde Paraguay que se encontraba en guerra civil; en las provincias andinas, como producto del paso de ciudadanos de los países limítrofes para realizar los trabajos de la zafra y en la Patagonia, resultado de la inmigración de arrieros o peones rurales temporarios, y un leve pero sostenido descenso de las cifras en el resto de las provincias. En el año 1953 el Ministerio de Salud Pública reconocía el éxito de su gestión, consignando que los índices de enfermos venéreos cada 10.000 habitantes habían descendido de 57,77 en el año 1947 a 23,02 en $1952.4^{49}$

Si la educación sanitaria y el tratamiento de las enfermedades venéreas fueron aceptados sin demasiadas discusiones, el tema más polémico fue el referido a una nueva reglamentación de la prostitución. La Secretaría de Salud Pública centró su preocupación en la relación directa entre prostitución clandestina e incremento de enfermedades venéreas. Para esta repartición oficial las fuentes más frecuentes de contagio eran las mujeres que trabajaban en los salones de baile, los "dancings" o las pensiones colectivas. Según datos recogidos en el Hogar San Miguel, donde la Policía Federal detenía a las mujeres por incitar a la prostitución en la vía pública, en 1947 el 44,47\% de estas trabajadoras poseía sífilis, la mayoría provenía del interior del país, era de condición humilde y "escudaba" en tareas del servicio doméstico la verdadera profesión que ejercía. A pesar de la insistencia de los funcionarios sanitarios para que asistieran a los dispensarios antivenéreos, la mayoría de ellas no lo hacía. De ahí que se habilitara un centro de Higiene Social en el mismo hogar, a fin de esterilizar el mal en las detenidas e impartirles educación sexual. Según los funcionarios sanitarios, después de iniciar el tratamiento específico en ese lugar, los exámenes serológicos indicaron un descenso del índice de sífilis. La solución para el responsable de la Dirección de Higiene Social "no se obtiene sólo con el tratamiento específico sino que hay que atacar las causas generadoras". Para ello sugiere internarlas en hogares colonias, bajo la vigilancia de visitadoras sociales, hasta que pudieran "adquirir hábitos de trabajo y moral". ${ }^{50}$

49 Camaño, Óscar; Serpa, Salvador, y Oscaris, Raúl: "Cuadros estadísticos de enfermos venéreos en la República Argentina”, ASSPN, vol. IV, n. ${ }^{\circ}$ 5, noviembre de 1948, págs. 441-448 y Ministerio de Salud Pública, Boletín del Día, Buenos Aires, 8 de octubre de 1953, pág. 1666.

50 Camaño, Óscar, y Rígoli, Juan: "Índice de morbilidad venérea en diferentes grupos sociales de la Capital Federal", ASSPN, vol. I, n. ${ }^{\circ} 7$, junio de 1947, págs. 23-28 y "Educación sanitaria...", pág. 460. 
El Secretario de Salud intervino personalmente dando su opinión acerca del sistema abolicionista. Según Carrillo, los límites de la ley 12.331 radicaban en que la "patología social de los abstinentes", las aberraciones sexuales y los delitos por ella provocados, se multiplicaban día a día durante los primeros años de su vigencia. De ahí que fuera necesario incorporarle las modificaciones de 1946 a partir de las cuales la prostitución podía existir siempre que no se le diera al sitio donde se ejercía carácter público u ostensible. Sin embargo, si para Carrillo las correcciones a la ley 12.331 resolvían problemas de índole moral, no daban respuesta a sus limitaciones sanitarias. Por eso propuso que, sin hacer una nueva normativa, los médicos realizaran controles periódicos y sistemáticos a las mujeres que trabajaban como prostitutas, amparados en las disposiciones que autorizaban a la autoridad sanitaria a efectuar la "policía de focos". De esta forma se llegaría a un sistema "reglamentarista por necesidad, abolicionista por moralidad". ${ }^{51}$

La labor parlamentaria acompañó los debates acerca de la necesidad de modificar el sistema abolicionista. Después de intensas discusiones en el Congreso Nacional y en la opinión pública, que incluyeron una fuerte oposición de la Iglesia Católica, la prostitución fue reglamentada en diciembre 1954. El decreto 22.532 autorizaba la apertura de las "casas de tolerancia" en virtud de atender a una "imperiosa necesidad pública". ${ }^{52}$ Con la reglamentación de la prostitución quedaba claro que, en los últimos años de la década peronista, las supuestas causas que daban origen a las enfermedades venéreas comenzaban a desaparecer del universo de preocupaciones de la gestión sanitaria. El uso sistemático de la penicilina para la cura de los "males secretos" dejaba de lado la preocupación por la prevención del contagio, aunque no la abandonaba totalmente, y centraba la atención en la localización de los enfermos y en la obligatoriedad de su cura. Por su parte, la venerología y la dermatosifilografía empezaban a desaparecer en el concierto de las especialidades médicas, absorbiendo la infectología el tratamiento de las enfermedades venéreas.

51 "El abolicionismo no excluye la policía sanitaria", $\operatorname{ASSPN}$, vol. IV, n. ${ }^{\circ} 5$, noviembre de 1948 , págs. 387-392.

52 Según Donna Guy, aunque tradicionalmente este decreto ha sido considerado parte del ataque del peronismo a la Iglesia Católica, y pese a la oposición de su jerarquía, resultaba compatible con las actitudes anteriores de los católicos hacia la prostitución: defender a la familia, a la sociedad y a la nación a través de la constitución de prostíbulos supervisados médicamente por la municipalidad: Guy, Donna: El sexo peligroso..., págs. 213-215 y 238-239. 


\section{Conclusiones}

En los años treinta se constituyeron nuevas agencias estatales que redefinieron muchas relaciones cruciales dentro de la sociedad civil, aún aquellas que se encontraban tradicionalmente ceñidas al ámbito de lo privado. En el área de las políticas sanitarias esa intervención se basó en los supuestos técnico-organizativos de los médicos. Utilizando sus antiguas redes de inserción profesional y política, estos expertos obtuvieron un acentuado protagonismo en la esfera estatal. Dos tópicos fueron recurrentes en su agenda: la necesidad de dotar al Estado de una organización centralizada y racional de la asistencia médico social y la resolución de la llamada "crisis poblacional", caracterizada por un descenso en los índices de natalidad, principalmente en las zonas prósperas, y un empobrecimiento biológico de la población. Sobre estos dos pilares el Departamento Nacional de Higiene sufrió una reorganización administrativa. La obtención de nuevas atribuciones y la sanción de leyes parlamentarias legitimaron aún más el lugar ocupado por estos especialistas en la esfera pública y las reformas que propusieron.

Las enfermedades venéreas fueron uno de los temas centrales abordados por la repartición sanitaria. Por un lado, la lectura alarmista respecto a la creciente cantidad de infectados y a las consecuencias genéticas para la salud de la población que el mal traería pusieron en evidencia la necesidad de una urgente e idónea intervención. Por otro lado, estaba claro que para conseguir óptimos y rápidos resultados debía apelarse a una acción coordinada y de relativo monopolio de autoridad.

El Departamento Nacional de Higiene se propuso, entonces, centralizar la prevención y el tratamiento de los "males secretos". Para ello contó con una ley nacional que creó y dotó de atribuciones y recursos a una de sus divisiones: la sección Dermatovenerológica. Creemos que el verdadero éxito de esta política sanitaria lejos de ser medido en términos de disminución de las dolencias venéreas - hacerlo significaría repetir la versión triunfalista de las parciales e incompletas estadísticas confeccionadas por la propia repartición y desconocer las limitaciones que el régimen abolicionista de la prostitución impuso al control de los padecimientos venéreosse vincula con su capacidad de imponer autoridad por encima de los niveles de asistencia regional y privada. Como ha intentado demostrar el trabajo, este logro estuvo asociado a su prerrogativa de administrar el presupuesto, distribuir los medicamentos e imponer un tratamiento estandarizado. 
A comienzos de la década de los cuarenta las críticas de orden moral y profiláctico al sistema abolicionista, junto con un leve rebrote de algunas enfermedades sexuales, acentuaron el tono represivo de la política orientada a la profilaxis venérea. La fiscalización sanitaria de las fronteras, el renovado control del ejercicio de la prostitución y la obligatoriedad de la denuncia, reclusión y tratamiento de aquellos que padecieran la enfermedad se dio en el marco de un Estado con sesgos crecientemente intervencionistas. De todos modos, el triunfo sobre los males venéreos conforme se avanza hacia los años cincuenta parece ligarse, tanto en Argentina como en el resto del mundo, al uso extendido de la penicilina. El descubrimiento y uso extendido de esta droga trajo asimismo consecuencias en la organización de las reparticiones sanitarias. La división antes encargada de la prevención y tratamiento de las enfermedades venéreas fue perdiendo cada vez más recursos y poder de determinación quedando subsumida a una nueva sección, Profilaxis Social, de funciones mucho más amplias.

Por último, en el trabajo se ha intentado vincular la política de centralización de la profilaxis venérea con el proceso de especialización de las disciplinas encargadas del tratamiento de las enfermedades sexuales y su consecuente reconocimiento oficial como especialidades médicas. Si bien en la década de los treinta y de los cuarenta este proceso de especialización y reconocimiento oficial fue muy marcado, estimulando y acompañando el diseño y ejecución de las políticas sanitarias estudiadas, a partir de la década de los cincuenta y conforme avanzó el uso extendido de la penicilina, estas disciplinas comenzaron a ser desplazadas por la inmunología. Este cambio no fue únicamente académico, sino que guardó una fuerte vinculación con la reestructuración del sistema sanitario en su conjunto. 